Accepted refereed manuscript of: Tumwesige V, Okello G, Semple S \& Smith J (2017) Impact of partial fuel switch on household air pollutants in sub-Sahara Africa, Environmental Pollution, 231, pp. 1021-1029. DOI: $\underline{\text { 10.1016/j.envpol.2017.08.118 }}$

(C) 2017, Elsevier. Licensed under the Creative Commons Attribution-NonCommercialNoDerivatives 4.0 International http://creativecommons.org/licenses/by-nc-nd/4.0/ 


\section{Impact of partial fuel switch on household air pollutants in sub-Sahara Africa.}

2

3 Authors: Vianney Tumwesige ${ }^{\mathrm{ac} *}$, Gabriel Okello ${ }^{\mathrm{bc}}$, Sean Semple ${ }^{\mathrm{b}}$, Jo Smith ${ }^{\mathrm{a}}$.

4

$5{ }^{\text {a }}$ Institute of Biological \& Environmental Science, University of Aberdeen, 23 St Machar

6 Drive, Aberdeen, AB24 3UU; ${ }^{\mathrm{b}}$ Institute of Applied Health Sciences, University of Aberdeen,

7 Westburn Road Aberdeen AB25 2ZG; ${ }^{\mathrm{c}}$ African Centre for Clean Air, Kampala-Uganda.

8

9

10

11 *Corresponding author: Vianney Tumwesige, University of Aberdeen, 23 St Machar Drive,

12 Aberdeen, AB24 3UU, UK. Tel: (+44) 1224 272702. Fax: (+44) 1224 272703. Email:

13 r01vt13@abdn.ac.uk; trustvianney@gmail.com. 


\section{ABSTRACT}

15 Over 700 million people in Sub-Saharan Africa depend on solid biomass fuel and use simple cookstoves in poorly ventilated kitchens, which results in high indoor concentrations of

17 household air pollutants. Switching from biomass to biogas as a cooking fuel can reduce

18 airborne emissions of fine particulate matter $\left(\mathrm{PM}_{2.5}\right)$ and carbon monoxide $(\mathrm{CO})$, but

19 households often only partially convert to biogas, continuing to use solid biomass fuels for part

20 of their daily cooking needs. There is little evidence of the benefits of partial switching to

21 biogas. This study monitored real-time $\mathrm{PM}_{2.5}$ and $\mathrm{CO}$ concentrations in 35 households in

22 Cameroon and Uganda where biogas and firewood (or charcoal) were used. The 24 hour mean

$23 \mathrm{PM}_{2.5}$ exposure in households that used: (1) firewood and charcoal, (2) both firewood (54\%

24 cooking time) and biogas (46\% cooking time) and (3) only biogas were $449 \mu \mathrm{g} \mathrm{m}^{-3}, 173 \mu \mathrm{g} \mathrm{m}^{-}$

$25{ }^{3}$ and $18 \mu \mathrm{g} \mathrm{m}^{-3}$ respectively. The corresponding 24 hour mean $\mathrm{CO}$ exposure was $14.2 \mathrm{ppm}, 2.7$

$26 \mathrm{ppm}$ and $0.5 \mathrm{ppm}$. The exposure was high and exceeded the World Health Organisation

27 guidelines when firewood and charcoal were used. Partially switching to biogas reduced CO

28 exposure to below the World Health Organisation guidelines, but $\mathrm{PM}_{2.5}$ concentrations were

29 only below the recommended limits when household fuel conversion was complete. These

30 results indicate that the partial switching from solid fuels to biogas was not sufficient and

31 results in concentrations of household air pollution that are likely to continue to harm the health

32 of those exposed. Households only achieved concentrations of $\mathrm{PM}_{2.5}$ that were below the

33 recommended limits when biogas was used to meet all cooking needs. Therefore, programmes

34 introducing biogas should aim to ensure that household energy needs can be fully achieved

35 using biogas with no requirement to continue using solid fuels. 
37 CAPSULE - When households in Uganda and Cameroon partially switched to biogas, the 38 carbon monoxide exposure was reduced to below the World Health Organisation guidelines,

39 but concentrations of particulate matter with an aerodynamic diameter of $2.5 \mu \mathrm{m}$ remained

40 above the recommended limits and only fell below this when household fuel conversion to 41 biogas was complete. 


\section{Introduction}

43 Over 700 million people in Sub-Saharan Africa (SSA) depend on solid biomass fuels to meet cooking and heating energy needs (Lambe et al., 2015; Mortimer et al., 2016; Ozturk and Bilgili, 2015; World Bank, 2012). Access to less polluting fuels is limited for the majority of the population in SSA (Rao and Pachauri, 2017) and so people tend to obtain their household energy from solid biomass fuels, such as wood, agricultural residues and animal wastes such as dung (Amegah and Agyei-Mensah, 2017; Sulaiman et al., 2017). Biomass fuels meet over 85\% of rural energy needs in SSA (Lambe et al., 2015; Mehetre et al., 2017; Rahut et al., 2017) compared to 37\% in Asia and 25\% in Latin America (Davidson, 1992; Dilaver et al., 2014; Mukhopadhyay et al., 2012; Sovacool, 2012). By contrast, in North America and Europe, the consumption of biomass fuel for cooking has been replaced by less polluting fuels, such as liquefied petroleum gas and electricity (Dilaver et al., 2014). The Cameroon and Uganda energy sectors are highly dependent on biomass, with over $91 \%$ of the total energy consumed in the country to meet basic energy needs for cooking and water heating coming from biomass.

A traditional three-stone cookstove, burning solid biomass fuel in a poorly ventilated kitchen is the most common method of cooking in SSA (Bruce et al., 2004; Jagger and Jumbe, 2016; Lambe et al., 2015; Po et al., 2011). These inefficient stoves are prearranged in a triangle using three large stones or bricks to hold the cooking pot. Solid biomass is burnt between the stones with generally incomplete combustion occurring and generating high amounts of household air pollutants (HAP). Two of the most frequently measured markers of HAP are fine particulate matter of $2.5 \mu \mathrm{m}$ aerodynamic diameter $\left(\mathrm{PM}_{2.5}\right)$ and carbon monoxide $(\mathrm{CO})$ (Bonjour et al., 2013; Jetter and Kariher, 2009; Nolte et al., 2001; Northcross et al., 2010, 2015). Globally, inhalation of HAP results in approximately 4 million premature deaths per year (Apple et al., 66 2010; Keil et al., 2010; Lewis et al., 2017; Mortimer et al., 2016; Olopade et al., 2017). 
Household air pollution is also associated with a range of conditions, including acute and chronic respiratory diseases, cardiovascular diseases, low-birth weight and cataracts (Anenberg et al., 2013; Gordon et al., 2014; Ezzati, 2001).

Guidance on appropriate exposure to $\mathrm{PM}_{2.5}$ and $\mathrm{CO}$ in inhaled air is provided by the World Health Organisation (WHO) (World Health Organization, 2016). To prevent harmful health consequences, the WHO recommends keeping $\mathrm{PM}_{2.5}$ concentrations at less than $25 \mu \mathrm{g} \mathrm{m}^{-3}$ when averaged over a 24 hour period, with the guidance also recommending CO should not exceed 6 ppm over 24 hours (World Health Organization, 2016).

In SSA, appropriate interventions, such as use of biogas as a cooking fuel, gasifier stoves and improved cookstoves can reduce airborne emissions of $\mathrm{PM}_{2.5}$ and CO (Dohoo et al., 2012; Maes and Verbist, 2012; Njenga et al., 2016; Semple et al., 2014) compared to biomass fuels such as firewood, charcoal and animal dung (Fullerton et al., 2009; Hankey et al., 2015). Biogas is a mixture of methane and carbon dioxide (Kinyua et al., 2016; Naik et al., 2014) that is produced when organic wastes, such as food leftovers, animal manure, human fecal matter or poultry droppings, are placed under anaerobic conditions and allowed to decompose (Surendra et al., 2014). Biogas can be burnt in a number of appliances such as biogas stoves (Tumwesige et al., 2014). These stoves have a better combustion efficiency with reduced emission of $\mathrm{PM}_{2.5}$ and CO compared to a three-stone fire. However, the impacts of introducing biogas in SSA on HAP concentrations, and consequently on human health, have not been studied in SSA. It is well understood that solid fuels have high emissions of $\mathrm{PM}_{2.5}$ and $\mathrm{CO}$ compared to gaseous fuels such as biogas, but the impacts on HAP of interventions to introduce biogas stoves, where household typically only partially switch to biogas is under-reported in SSA. In this study, households used biogas to prepare breakfast, firewood was used to prepare lunch, heating of 
92 bathing water is done on biogas, and smoldering (a method used to keep evening meals warm)

93 was done using firewood. In this paper, we examine the impact of this type of partial switching 94 on exposure to HAP.

95

96

Page $\mathbf{7}$ of $\mathbf{3 1}$ 


\section{Materials and methods}

\subsection{Study population and sampling techniques}

Measurements of indoor $\mathrm{PM}_{2.5}$ and $\mathrm{CO}$ were taken from households in Cameroon and Uganda

100 in areas where biogas digesters had previously been installed.

101

102 In Cameroon, Adamawa province was selected. This province borders the central and eastern 103 provinces to the south, the northwest and west provinces to the southwest, Nigeria to the west and the Central African Republic to the east. Adamawa is mountainous with a land area of $64,000 \mathrm{~km}^{2}$, and the land is sparsely populated. Cattle production is the major agricultural activity. The Fulani is the major ethic group in the province. This province was purposively

107 selected because SNV and Wageningen University, Netherlands had specifically promoted and installed biogas digesters in the area to investigate the effect of subsidies on the uptake and implementation of innovative technology in a development context. Eighteen households were randomly selected from the list of households with and without installed digesters. These

111 households were recruited to the study between April and May 2015 after consent was given

112 by an adult in the household. Nine households used either charcoal or firewood and nine

113 households used biogas for cooking.

115 "In Uganda, Kikati in Najjembe Sub-County in Buikwe district was purposively selected for 116 the study. This area was selected because it had been specifically targeted by local 117 organizations promoting biogas technology. Kikati is found $51 \mathrm{~km}$ along Kampala-Jinja 118 highway. The village has approximately 400 households. Baseline HAP concentrations were 119 sampled between March and May 2014. Consent was given by an adult in the household.

120 Eighteen households were randomly selected from lists of households with and without 121 digesters and recruited for the study; three of the households were already using biogas and 
122 wood to meet cooking energy demand. Between August and December 2015, HAP was

123 measured in a) five households that switched from wood to biogas for cooking, b) nine

124 households that used wood as a cooking fuel and c) three households that used both biogas and

125 wood as cooking fuels. One household declined to participate in the post-biogas installation

126 measurements.

127

128 Measurement devices (see section 2.2 below) were placed in the room designated as the

129 primary cooking space and at a height of approximately $1 \mathrm{~m}$ and typically $1.5 \mathrm{~m}$ from the

130 cookstove. Measurements of $\underline{\mathrm{PM}_{2.5}}$ and $\mathrm{CO}$ were taken over a 24 hour period.

\subsection{Data collection}

\subsubsection{Kitchen description}

134 In all households under study, the kitchen features including the type of stove, fuel use, type of

135 food cooked, duration of cooking, kitchen design, the cooking area, windows, doors, height

136 from floor to roof, walls, seats ventilation (spaces in kitchen walls), kitchen volume, number

137 of windows, door and window size (dimensions) were obtained through measurement, observation and interview with both household head and the principal cook. The kitchen volume ranged from 4.3-10.2 $\mathrm{m}^{3}$ (average $7.4 \mathrm{~m}^{3}$ ). A traditional three-stone cookstove placed

140 less than a metre from the wall was used by all households that used wood prior to adopting

141 biogas for cooking. In all households, meal preparation was done inside the kitchen, which was

142 built out of unbaked or mud bricks located within a 1-5 m radius from the residential house. It

143 was observed that all kitchens had a door which was kept open during meal preparations.

144 Thirteen households had a window on their kitchens compared to 22 without a window. The

145 door and the window in the kitchen were used for ventilation.

146 


\subsubsection{Household characteristics and cooking activity}

148 The number of people in the household, weight of firewood and number of people present in

149 the kitchen during cooking were recorded for each household. In all households, an average of

150 three meals was prepared by children between age of 10-16 years and adult females above the

151 age of 18 years. Breakfast was prepared between 07:00-11:00; lunch was prepared between

152 11:00-15:00 and dinner prepared between 18:00-21:00. Smoulding was the only method used

153 to keep evening meals warm. It was further observed that meals especially breakfast for non-

154 school-going children was served in the kitchen while the women peels fruit and vegetables

155 and prepares sauces, especially from dried beans which require 2-3 hours of cooking.

156

157 In Cameroon, men have a special dining area separate from dining area for children and women. In Uganda, men have a special dining seat or table while children and women usually sit on mats laid on the floor. In households where men returned home late, either from work or social events, dinner is served inside the kitchen for children and sometimes women.

\subsubsection{Household air pollution measurements}

Household air pollution was assessed by measuring the airborne concentration of $\mathrm{PM}_{2.5}$ and $\mathrm{CO}$ under the prevailing conditions of the kitchen of each household. No burning or ventilation behaviours were controlled. A TSI SidePak AM510 (TSI Inc, CA, USA) was used to measure mass concentration of $\mathrm{PM}_{2.5}$. A CO data logger (LASCAR EL-USB-CO) with a measurement range of 0-1000 ppm was used to measure household levels of CO. Both devices measured concentrations every 1 second and recorded the average value every minute.

170 The collected data were downloaded using proprietary software (TSI TrakPro Ver. 4.5.1.0); average (arithmetic mean) concentrations and maximum concentrations were identified for 
172 each home. The $\mathrm{PM}_{2.5}$ concentrations collected by the SidePak were corrected by a factor of 1730.295 (Jiang et al., 2011) to account for the difference in particle characteristics, including 174 density, size distribution and or index of refraction. The percentage of time when $\mathrm{PM}_{2.5}$ 175 measurements exceeded the two thresholds, the WHO 24-hour guidance limit $\left(25 \mu \mathrm{g} \mathrm{m}^{-3}\right)$ and 176 the US Environmental Protection Agency (US-EPA) 24-hour hazardous level $\left(250 \mu \mathrm{g} \mathrm{m}^{-3}\right)$,

177 were also recorded for each sampling period. The CO data were downloaded using proprietary 178 software (EasyLog USB Ver. 7.2.0.0) with $24 \mathrm{~h}$ arithmetic mean, maximum and percentage of 179 time $>6 \mathrm{ppm}$ derived from the resulting data log.

180

\subsection{Particulate matter and carbon monoxide analysis}

The $24 \mathrm{~h}$ averages for $\mathrm{PM}_{2.5}$ and $\mathrm{CO}$ concentration data were generated for each household together with minimum and maximum concentrations. The mean and standard deviations for each household were calculated and statistical tests used to determine if there were significant differences in $\mathrm{PM}_{2.5}$ and $\mathrm{CO}$ concentrations in kitchens that used biogas for cooking and similar homes using firewood as cooking fuels in both Cameroon and Uganda.

\subsection{Statistical analysis}

189 The HAP data were verified and then analysed using MS Excel 2010, (Microsoft Corp).

190 Proportions were compared using the Student's t-test to determine differences between 191 households using various fuel types.

\subsection{Ethics approval}

194 Written and verbal consent for participation in this study was obtained from all volunteers. The

195 study was given ethical approval from the College Ethics Review Board of the University of 196 Aberdeen. 


\section{Results}

201 Table 1 presents the $\mathrm{PM}_{2.5}$ concentrations of the 18 households in Adamawa and Kikati which used firewood and charcoal to meet all cooking needs. The average mean $\mathrm{PM}_{2.5}$ concentration was $387 \mu \mathrm{g} \mathrm{m}^{-3}$ in households in Adamawa and $511 \mu \mathrm{g} \mathrm{m}^{-3}$ in Kikati. All wood and charcoal

204 burning households in both countries had mean $\mathrm{PM}_{2.5}$ concentrations above the WHO guideline of $25 \mu \mathrm{g} \mathrm{m}^{-3}$. A Student's t-test indicated that there was no statistically significant difference in $\mathrm{PM}_{2.5}$ concentration between households using firewood in Adamawa and Kikati $(\mathrm{p}=0.29)$.

TABLE 1

210 Table 2 presents the $\mathrm{CO}$ concentrations of 16 households in Adamawa and Kikati which used 211 firewood to meet all cooking needs. The average value for the 24 hour mean CO concentration

212 in homes in Kikati was 11.5 ppm, while in Adamawa it was 16.8 ppm. All households in 213 Adamawa and Kikati had mean exposure levels above the WHO guideline of 6 ppm CO. A 214 Student's t-test indicated that there was no statistically significant difference in CO 215 concentrations between households in Adamawa and Kikati $(\mathrm{p}=0.31)$.

216

TABLE 2

218

219 Figure 1 shows the measured the $\mathrm{PM}_{2.5}$ and $\mathrm{CO}$ data for one typical wood burning household 220 in Adamawa over a 20 hour period. This typical wood burning household, CHH14 had a mean $221 \mathrm{PM}_{2.5}$ of $666 \mu \mathrm{g} \mathrm{m}^{-3}$, standard deviation of 1232, the mean $\mathrm{CO}$ of $11.5 \mathrm{ppm}$ and standard 222 deviation of 18.9 .

223 
224 Table 3 presents the $\mathrm{PM}_{2.5}$ concentrations of five households in Kikati which switched from 225 firewood to biogas as a cooking fuel. The average value for the 24 hour mean $\mathrm{PM}_{2.5}$

226 concentration for the five households before switching to biogas was $444 \mu \mathrm{g} \mathrm{m}^{-3}$, and this 227 reduced to $173 \mu \mathrm{g} \mathrm{m}^{-3}$ after the switch. A Student's t-test indicated that this difference was not 228 statistically significant $(\mathrm{p}=0.055)$.

TABLE 3

In Adamawa, households using biogas only (excluding CHH16) had mean $\mathrm{PM}_{2.5}$ concentrations of $18 \mu \mathrm{g} \mathrm{m}^{-3}$. Household $\mathrm{CHH} 16$ had a higher concentration with a mean $\mathrm{PM}_{2.5}$ value of $38.6 \mu \mathrm{g} \mathrm{m}^{-3}$. The high levels in this house were likely to be due to a traditional medical treatment being used during the sampling time which involved smoldering charcoal, so this household was excluded from the analysis.

Table 4 presents the $\mathrm{CO}$ concentrations of five households in Kikati which switched from firewood to biogas as a cooking fuel. The average value of the 24 hour mean $\mathrm{CO}$ concentration for the five households before switching to biogas was $22 \mathrm{ppm}$ reducing to $2.7 \mathrm{ppm}$ after the switch. A Student's t-test indicated that there was a statistically significant difference in CO concentration in households in Kikati that switched from firewood to biogas for cooking $(\mathrm{p}=0.042)$.

TABLE 4

247 In Adamawa, households using biogas only (excluding $\mathrm{CHH}_{16}$ ) had mean $\mathrm{PM}_{2.5}$ 248 concentrations of $18 \mu \mathrm{g} \mathrm{m}^{-3}$ (Table 5). Household CHH16 had a higher concentration with a 
mean $\mathrm{PM}_{2.5}$ value of $38.6 \mu \mathrm{g} \mathrm{m}^{-3}$. The high levels in this house were likely to be due to a traditional medical treatment being used during the sampling time which involved smoldering charcoal, so this household was excluded from the analysis.

TABLE 5

With the exception of household CHH16, all households in Adamawa using biogas only had a mean $\mathrm{CO}$ value of less than $1 \mathrm{ppm}$ (Table 5); this is below the WHO guideline of $6 \mathrm{ppm}$. Household CHH16 had a higher exposure with mean $\mathrm{CO}$ value of $25 \mathrm{ppm}$.

Figure 2 shows the measured the $\mathrm{PM}_{2.5}$ and $\mathrm{CO}$ data over a 20 hour period for one typical household (CHH06) in Adamawa that uses biogas for cooking. Household CHH06 had a mean $\mathrm{PM}_{2.5}$ of $14 \mu \mathrm{g} \mathrm{m}^{-3}$, standard deviation of 23 , the mean $\mathrm{CO}$ of $1.1 \mathrm{ppm}$ and standard deviation of 4.4 .

FIGURE 2

266 Households in Adamawa had a $\mathrm{PM}_{2.5}$ value of $464 \mu \mathrm{g} \mathrm{m}^{-3}$ compared to households in Kikati, 267 which had a mean $\mathrm{PM}_{2.5}$ value of $154 \mu \mathrm{g} \mathrm{m}^{-3}$. A Student's t-test indicated that there was no 268 statistically significant difference (in $\mathrm{PM}_{2.5}$ concentration when households used both wood and biogas to meeting their cooking needs $(\mathrm{p}=0.36)$. In both villages, the mean $\mathrm{PM}_{2.5}$ remained high in households when a combination of biogas and wood was used to meet cooking needs,

271 this is comparable to results in Table 1. The results in Table 6 demonstrate that improvements

272 in household air quality are not apparent if firewood and biogas are both used for cooking at 273 the same time. 
TABLE 6

276

277 Figures 3 shows the mean $\mathrm{PM}_{2.5}$ in the 18 households in Adamawa.

278

FIGURE 3

280

281

\section{Discussion}

282 The results of this study provide real-time $\mathrm{PM}_{2.5}$ and $\mathrm{CO}$ concentrations in Adamawa and 283 Kikati, villages in Cameroon and Uganda respectively. The study compares the impact of cooking with biogas, firewood, and a mixture of biogas and firewood on indoor air quality in kitchens in households in two countries in SSA. Households collected firewood either in the gardens or from forest cleared for agriculture; they cited reduction in smoke in their kitchens as a motivating factor for switching from firewood to biogas.

\subsection{Biomass fuel: before biogas installation}

In Adamawa and Kikati, households that used firewood and charcoal had a 24 h average $\mathrm{PM}_{2.5}$ concentration of 387 and $511 \mu \mathrm{g} \mathrm{m}^{-3}$ respectively. Data for CO was $11.5 \mathrm{ppm}$ (Adamawa) to 16.8 ppm (Kikati). These HAP concentrations are high and exceed the WHO guideline of 25 $\mu \mathrm{g} \mathrm{m}^{-3}$ for $\mathrm{PM}_{2.5}$ and $6 \mathrm{ppm}$ for $\mathrm{CO}$ concentration suggesting a serious health risk to the women and children who spend most of their time in the kitchen during cooking hours (Devakumar et al., 2014; Thorsson et al., 2014). Comparable $\mathrm{PM}_{2.5}$ results are summarised in Table 7 and

296 previously reported by Hankey et al., (2015); Keil et al., (2010); Pennise et al., (2009);

297 Titcombe and Simcik, (2011) among other studies. A number of factors such as fuel type, 298 cooking period, food to be cooked, season, location (e.g. rural, urban) are likely to impact on 
the concentration of $\mathrm{PM}_{2.5}$ in households as shown in studies by Sanbata et al., (2014) in Addis

300 Ababa, Fullerton et al., (2009) in Malawi, Kurmi et al., (2008) in Nepal and Zhou et al., (2011)

301 in Ghana.

303 It was observed that kitchens in Adamawa and Kikati had poor ventilation, generally with one

304 small window or ventilator. Improving ventilation in these rural household kitchens would decrease concentrations of $\mathrm{PM}_{2.5}$ and CO in household air (Smith et al., 2010). Also, Mortimer, et al., (2016) reported that introduction of improved cookstove in households did not reduce the risk of chronic obstractive disease in children below the age of five.

\subsection{Partial fuel switch}

310 In households using both biogas and firewood, it was observed during the study, digesters in 311 these households were not producing enough biogas for a full day of cooking. This was

312 attributed to limited availability of organic waste and increased labour requirements for 313 digester maintenance, mainly due to the need to collect extra water for biogas production.

314 Therefore, installation of biogas digesters in these households had limited impact on the use of

315 firewood. It was also observed that households used firewood to cook and steam specific food types, for example, matooke in Kikati and fufu in Adamawa, but biogas was used to cook vegetables, porridge and boil water for tea or coffee.

319 Households using both biogas and firewood (Table 6) had a $24 \mathrm{~h}$ average $\mathrm{PM}_{2.5}$ concentrations 320 of $464 \mu \mathrm{g} \mathrm{m}^{-3}$ (in Adamawa) and $154 \mu \mathrm{g} \mathrm{m}^{-3}$ in Kikati similar to households using firewood only (Tables 1 and 2). On average, households obtained $48 \%$ of their cooking time from solid biomass fuels, and 52\% from biogas (Tumwesige, 2017). Simple changes to the infrastructure of households, for example improved ventilation in the kitchen or use of efficient cookstoves, 
coupled with education to help householders make better use of these changes would further reduce HAP concentrations.

\subsection{Fuel switching}

In Adamawa and Kikati, the drivers for deciding to install a biogas digester were: (i) alternative and sustainable energy source that can reduce smoke in their kitchens; (ii) organic fertilizer for resource recovery, reuse and recycling; and (iii) on-site waste management for effective and sustainable waste disposal. In Kikati, switching from firewood to biogas for cooking saw a reduction in the average 24 hour $\mathrm{PM}_{2.5}$ and $\mathrm{CO}$ concentrations to $173 \mu \mathrm{g} \mathrm{m}^{-3}$ and $2.7 \mathrm{ppm}$ respectively. The CO levels were reduced to below the WHO guidelines, but the $\mathrm{PM}_{2.5}$ levels remained above than the WHO limit (Bruce et al., 2015). In Adamawa, households using biogas only (with the exception of $\mathrm{CHH} 16$ ) had mean $\mathrm{PM}_{2.5}$ and $\mathrm{CO}$ concentrations of $18 \mu \mathrm{g}$ $\mathrm{m}^{-3}$ and $0.5 \mathrm{ppm}$. These are below the WHO guidelines for $\mathrm{PM}_{2.5}$ and $\mathrm{CO}$ of $25 \mu \mathrm{g} \mathrm{m}^{-3}$ and 6 ppm respectively. In the study by Titcombe and Simcik, (2011), the use of liquid petroleum gas was found to produce $\mathrm{PM}_{2.5}$ concentrations of $14 \mu \mathrm{g} \mathrm{m}^{-3}$, comparable those produced by biogas in Adamawa.

The use of biogas for cooking is a positive step towards achieving clean cooking and reductions in HAP concentrations. Our results suggest that use of biogas as a cooking fuel can reduce HAP concentrations and is therefore likely to produce health benefits associated with reduced exposure to fine particulate matter and CO. A study by Dohoo et al., (2012), revealed that women reported fewer respiratory symptoms after the installation of biogas digesters.

346 Households in Adamawa and Kikati had a significant reduction in $\mathrm{PM}_{2.5}$ and $\mathrm{CO}$ exposure.

347 This could lead to reduced risk of pneumonia, blood pressure and heart problems (Gordon et al., 2014; Semple et al., 2014, 2016). Households in Adamawa and Kikati still used other fuels, 
such as kerosene, for lighting in the evenings; switching to use of solar lamps could further reduce HAP concentrations.

A purposive sampling method was used to select the study areas, so results are limited to study areas with similar characteristics. Studies areas were in rural locations without contamination from vehicles and industries. The household kitchen volume varied from $4.3-10.2 \mathrm{~m}^{3}$, this is cited as a limitation of the study, comparable kitchen volumes would have been ideal.

Further limitations of this study include a lack of comparative data for indoor $\mathrm{PM}_{2.5}$ and $\mathrm{CO}$ concentrations in households in other SSA countries switching from biomass fuels to biogas for cooking. In Adamawa, biogas digesters had been in use for a longer period before the study was under taken than in Kikati. In Kikati, the average 24 hour $\mathrm{PM}_{2.5}$ concentration was $173 \mu \mathrm{g}$ $\mathrm{m}^{-3}$ compared to only $18 \mu \mathrm{g} \mathrm{m}^{-3}$ in Adamawa. Households in Adamawa had more experience in maintaining biogas digesters than those in Kitaki, where digesters had been installed only 5 months before the study was undertaken.

The duration of sampling was another limitation. Measurements were done over a 24 hour period, this could have lad to behavior change in homes under study. Barnes et al. (2011) provided evidence that behavioural change interventions within biomass burning households had the potential to reduce HAP.

Data on exposure to $\mathrm{PM}_{2.5}$ and $\mathrm{CO}$ was measured after biogas digesters were installed in

371 Adamawa; these household were matched with those without biogas digesters. To allow direct

372 comparison, it would have been better to measure $\mathrm{PM}_{2.5}$ and $\mathrm{CO}$ prior to biogas installation 373 and again once the installation has been completed. In Kikati, indoor air quality was measured 

comparison. Availability of funds precluded installation of additional biogas digesters in

Cameroon.

378 Another limitation is the small number of households in the study. We had anticipated that we would work with 48 households before and after biogas digesters were installed in Kikati. These were to be paired with 48 households without intervention. However, the high cost of installing digesters prohibited a study of this size.

\section{Conclusion}

384 Household $\mathrm{PM}_{2.5}$ concentrations significantly decreased when households in Kikati switched

385 from use of firewood to biogas for cooking. Use of biogas in Adamawa resulted in low $\mathrm{PM}_{2.5}$ and $\mathrm{CO}$ concentrations. To the best of our knowledge, this is the only study in SSA documenting the cross sectional impact of when households use only solid biomass fuel, only biogas and use both solid biomass fuel and biogas. Small reductions in concentrations of HAP can have a large impact on livelihoods. By the end of 2016, the 57,000 biogas digesters had

390 been installed in a number of SSA countries (ABPP, 2016). As biogas digesters adoption

391 increases in SSA, the average HAP exposure of households will be impacted as a result of households switching from firewood to biogas as a cooking fuel, although this will often only

393 be a partial switch. This study provides evidence for the impacts of partial conversion to biogas.

394 Women and children will spend less time in polluted kitchens, but the study demonstrates that 395 the potential benefits of reduced concentrations of HAP will not be fully realized if households 396 use both firewood and biogas for cooking at the same time. Longer follow-up will be needed to detect statistically significant changes of HAP in larger household size in SSA. Furthermore, 
398 there is need to monitor personal exposure associated with cooking fuel switch in different 399 household age groups.

400

401 


\section{Acknowledgments}

403

404 The authors acknowledge the support provided by the European Union through the African 405 Component of the ACP Research Programme for Sustainable Development as well as the 406 African Union Commission (No. AURG/2/058/2012). Furthermore we are grateful to Afri407 Flame network, Esther Pedie, Thierry Tame, Niccolo Merigi and Jelte Harnmeijer for their 408 collaboration, contributing their knowledge, experiences and opinions.

409 


\section{References}

411 ABPP. (2016) Biogas digesters installation in sub-Saharan Africa, Available from: http://www.africabiogas.org/biogas-plants-per-country/ (accessed 1 February 2017).

Amegah, A.K. and Agyei-Mensah, S. (2017) Urban air pollution in Sub-Saharan Africa: Time for action, Environmental Pollution, 738-743.

Anenberg, S.C., Balakrishnan, K., Jetter, J., Masera, O., Mehta, S., Moss, J. and Ramanathan, V. (2013) Cleaner Cooking Solutions to Achieve Health, Climate, and Economic Cobenefits, Environ. Sci. Technol., American Chemical Society, 47, 3944-3952, Available from: http://pubs.acs.org/doi/abs/10.1021/es304942e (accessed 8 February 2017).

Apple, J., Vicente, R., Yarberry, A., Lohse, N., Mills, E., Jacobson, A. and Poppendieck, D. (2010) Characterization of particulate matter size distributions and indoor concentrations from kerosene and diesel lamps, Indoor Air, 20, 399-411.

Bonjour, S., Adair-Rohani, H., Wolf, J., Bruce, N.G., Mehta, S., Prüss-Ustün, A., Lahiff, M., Rehfuess, E.A., Mishra, V. and Smith, K.R. (2013) Solid Fuel Use for Household Cooking: Country and Regional Estimates for 1980-2010, Environ. Health Perspect., 121, 784-790.

Bruce, N., McCracken, J., Albalak, R., Schei, M.A., Smith, K.R., Lopez, V. and West, C. (2004) Impact of improved stoves, house construction and child location on levels of indoor air pollution exposure in young Guatemalan children, J. Expo. Anal. Environ.

from: http://www.nature.com/doifinder/10.1038/sj.jea.7500355.

Bruce, N., Pope, D., Rehfuess, E., Balakrishnan, K., Adair-Rohani, H. and Dora, C. (2015) WHO indoor air quality guidelines on household fuel combustion: Strategy implications of new evidence on interventions and exposure-risk functions, Atmos. Environ., 106, 451- 
Davidson, O. (1992) Energy Issues in Sub-Saharan Africa: Future Directions, Annu. Rev. Energy Environ., 17, 359-403.

Devakumar, D., Semple, S., Osrin, D., Yadav, S.K., Kurmi, O.P., Saville, N.M., Shrestha, B., Manandhar, D.S., Costello, A. and Ayres, J.G. (2014) Biomass fuel use and the exposure of children to particulate air pollution in southern Nepal, Environ. Int., 66, 79-87.

Dilaver, Ö., Dilaver, Z. and Hunt, L.C. (2014) What drives natural gas consumption in Europe? Analysis and projections, J. Nat. Gas Sci. Eng., 19, 125-136.

Dohoo, C., Guernsey, J.R., Critchley, K. and Vanleeuwen, J. (2012) Pilot study on the impact of biogas as a fuel source on respiratory health of women on rural Kenyan smallholder dairy farms, J. Environ. Public Health, 2012.

Fullerton, D.G., Semple, S., Kalambo, F., Suseno, A., Malamba, R., Henderson, G., Ayres, J.G. and Gordon, S.B. (2009) Biomass fuel use and indoor air pollution in homes in Malawi., Occup. Environ. Med., 66, 777-783.

Gordon, S.B., Bruce, N.G., Grigg, J., Hibberd, P.L., Kurmi, O.P., Lam, K.H., Mortimer, K., 450

Hankey, S., Sullivan, K., Kinnick, A., Koskey, A., Grande, K., Davidson, J.H. and Marshall, J.D. (2015) Using objective measures of stove use and indoor air quality to evaluate a cookstove intervention in rural Uganda, Energy Sustain. Dev., International Energy Initiative, 25, 67-74, Available from: http://dx.doi.org/10.1016/j.esd.2014.12.007. 
in Malawi, Energy Policy, Elsevier, 92, 409-419, Available from: http://dx.doi.org/10.1016/j.enpol.2016.02.034.

462

Jetter, J.J. and Kariher, P. (2009) Solid-fuel household cook stoves: Characterization of performance and emissions, Biomass and Bioenergy, Elsevier Ltd, 33, 294-305, Available from: http://dx.doi.org/10.1016/j.biombioe.2008.05.014.

Jiang, R.T., Acevedo-Bolton, V., Cheng, K.C., Klepeis, N.E., Ott, W.R. and Hildemann, L.M. (2011) Determination of response of real-time SidePak AM510 monitor to secondhand smoke, other common indoor aerosols, and outdoor aerosol, J. Environ. Monit., 13, 1695, Available from: http://xlink.rsc.org/?DOI=c0em00732c (accessed 8 February 2017).

Keil, C., Kassa, H., Brown, A., Kumie, A. and Tefera, W. (2010) Inhalation exposures to particulate matter and carbon monoxide during Ethiopian coffee ceremonies in Addis Ababa: A pilot study, J. Environ. Public Health, 2010, Available from: http://dx.doi.org/10.1155/2010/213960

Kinyua, M.N., Rowse, L.E. and Ergas, S.J. (2016) Review of small-scale tubular anaerobic digesters treating livestock waste in the developing world, Renew. Sustain. Energy Rev., 58, 896-910.

Kurmi, O.P., Semple, S., Steiner, M., Henderson, G.D. and Ayres, J.G. (2008) Particulate matter exposure during domestic work in Nepal, Ann. Occup. Hyg., 52, 509-517.

Lambe, F., Jürisoo, M., Wanjiru, H. and Senyagwa, J. (2015) Bringing clean, safe, affordable cooking energy to households across Africa : an agenda for action, New Clim. Econ., 132.

Lewis, J.J., Hollingsworth, J.W., Chartier, R.T., Cooper, E.M., Foster, W.M., Gomes, G.L., Kussin, P.S., MacInnis, J.J., Padhi, B.K., Panigrahi, P., Rodes, C.E., Ryde, I.T., Singha, A.K., Stapleton, H.M., Thornburg, J., Young, C.J., Meyer, J.N. and Pattanayak, S.K. 
(2017) Biogas Stoves Reduce Firewood Use, Household Air Pollution, and Hospital Visits in Odisha, India, Environ. Sci. Technol., American Chemical Society, 51, 560-569, Available from: http://pubs.acs.org/doi/abs/10.1021/acs.est.6b02466 (accessed 8 February 2017).

Maes, W.H. and Verbist, B. (2012) Increasing the sustainability of household cooking in developing countries: Policy implications, Renew. Sustain. Energy Rev., 16, 4204-4221.

Ezzati, D.M.K. (2001) Indoor air pollution from biomass combustion and acute respiratory infections in Kenya: an exposure-response study, Lancet, 358, 619-624.

Mehetre, S.A., Panwar, N.L., Sharma, D. and Kumar, H. (2017) Improved biomass cookstoves for sustainable development: A review, Renew. Sustain. Energy Rev., 73, 672-687.

Mortimer, K., Ndamala, C.B., Naunje, A.W., Malava, J., Katundu, C., Weston, W., Havens, D., Pope, D., Bruce, N.G., Nyirenda, M., Wang, D., Crampin, A., Grigg, J., Balmes, J. and Gordon, S.B. (2016) A cleaner burning biomass-fuelled cookstove intervention to prevent pneumonia in children under 5 years old in rural Malawi (the Cooking and Pneumonia Study): a cluster randomised controlled trial, Lancet, 6736, 1-9, Available from: http://linkinghub.elsevier.com/retrieve/pii/S0140673616325077.

Mortimer, K., Lim, S., Vos, T., Flaxman, A., Gordon, S., Bruce, N., Grigg, J., Mortimer, K., Gordon, S., Jindal, S., Smith, K., McCracken, J., Weber, M., Jetter, J., Zhao, Y. and Smith, K. (2016) Chimney stove intervention--ready for scale up? CON., Thorax, BMJ Publishing Group Ltd, 71, 391-2, Available from: http://www.ncbi.nlm.nih.gov/pubmed/26966236 (accessed 8 February 2017).

Mukhopadhyay, R., Sambandam, S., Pillarisetti, A., Jack, D., Mukhopadhyay, K., Balakrishnan, K., Vaswani, M., Bates, M.N., Kinney, P.L., Arora, N. and Smith, K.R. (2012) Cooking practices, air quality, and the acceptability of advanced cookstoves in Haryana, India: an exploratory study to inform large-scale interventions., Glob. Health 
511 Naik, L., Gebreegziabher, Z., Tumwesige, V., Balana, B., Mwirigi, J. and Austin, G. (2014)

512 Factors determining the stability and productivity of small scale anaerobic digesters, $513 \quad$ Biomass and Bioenergy, 70, 51-57.

514 Njenga, M., Iiyama, M., Jamnadass, R., Helander, H., Larsson, L., de Leeuw, J., Neufeldt, H., 515 Röing de Nowina, K. and Sundberg, C. (2016) Gasifier as a cleaner cooking system in 516 rural Kenya, J. Clean. Prod., 121, 208-217.

517 Nolte, C.G., Schauer, J.J., Cass, G.R. and Simoneit, B.R.T. (2001) Highly polar organic 518 compounds present in wood smoke and in the ambient atmosphere, Environ. Sci. Technol., $519 \quad 35,1912-1919$.

520 Northcross, A., Chowdhury, Z., McCracken, J., Canuz, E. and Smith, K.R. (2010) Estimating personal PM2.5 exposures using CO measurements in Guatemalan households cooking with wood fuel., J. Environ. Monit., 12, 873-878.

Northcross, A.L., Hwang, N., Balakrishnan, K. and Mehta, S. (2015) Assessing exposures to household air pollution in public health research and program evaluation., Ecohealth, Springer, 12, 57-67, Available from: http://www.ncbi.nlm.nih.gov/pubmed/25380652 (accessed 8 February 2017).

Olopade, C.O., Frank, E., Bartlett, E., Alexander, D., Dutta, A., Ibigbami, T., Adu, D., Olamijulo, J., Arinola, G., Karrison, T. and Ojengbede, O. (2017) Effect of a clean stove intervention on inflammatory biomarkers in pregnant women in Ibadan, Nigeria: A randomized controlled study, Environ. Int., 98, 181-190.

Ozturk, I. and Bilgili, F. (2015) Economic growth and biomass consumption nexus: Dynamic panel analysis for Sub-Sahara African countries, Appl. Energy, 137, 110-116.

533 Pennise, D., Brant, S., Agbeve, S.M., Quaye, W., Mengesha, F., Tadele, W. and Wofchuck, T. (2009) Indoor air quality impacts of an improved wood stove in Ghana and an ethanol 
Po, J.Y.T., FitzGerald, J.M. and Carlsten, C. (2011) Respiratory disease associated with solid biomass fuel exposure in rural women and children: systematic review and meta-analysis., Thorax, 66, 232-239.

Rahut, D.B., Behera, B. and Ali, A. (2017) Factors determining household use of clean and renewable energy sources for lighting in Sub-Saharan Africa, Renew. Sustain. Energy Rev., 72, 661-672.

Rao, N. and Pachauri, S. (2017) Energy access and living standards: some observations on recent trends, Environ. Res. Lett., IOP Publishing, Available from:

Sanbata, H., Asfaw, A. and Kumie, A. (2014) Association of biomass fuel use with acute respiratory infections among under- five children in a slum urban of Addis Ababa, Ethiopia, BMC Public Health, 14, 1122, Available from: http://dx.doi.org/10.1186/14712458-14-1122.

Semple, S., Apsley, A., Wushishi, A. and Smith, J. (2014) Commentary: Switching to biogas - What effect could it have on indoor air quality and human health?, Biomass and Bioenergy, 70, 125-129.

Semple, S., Devakumar, D., Fullerton, D.G., Thorne, P.S., Costello, A., Gordon, S.B., Manandhar, D.S., Ayres, J.G., Sem, S., Fullerton, D.G., Thorne, P.S., Metwali, N., Costello, A., Gordon, S.B., Manandhar, D.S. and Ayres, J.G. (2016) Linked references

Smith, K.R., McCracken, J.P., Thompson, L., Edwards, R., Shields, K.N., Canuz, E. and Bruce, are available on JSTOR for this article : Airborne Endotoxin Concentrations in Homes N. (2010) Personal child and mother carbon monoxide exposures and kitchen levels: methods and results from a randomized trial of woodfired chimney cookstoves in 

February 2017).

Sovacool, B.K. (2012) The political economy of energy poverty: A review of key challenges, Energy Sustain. Dev., 16, 272-282.

Sulaiman, C., Abdul-Rahim, A.S., Mohd-Shahwahid, H.O. and Chin, L. (2017) Wood fuel consumption, institutional quality, and forest degradation in sub-Saharan Africa: Evidence from a dynamic panel framework, Ecol. Indic., 74, 414-419.

Surendra, K.C., Takara, D., Hashimoto, A.G. and Khanal, S.K. (2014) Biogas as a sustainable energy source for developing countries: Opportunities and challenges, Renew. Sustain. Energy Rev., 31, 846-859.

Thorsson, S., Holmer, B., Andjelic, A., Lindén, J., Cimerman, S. and Barregard, L. (2014) Carbon monoxide concentrations in outdoor wood-fired kitchens in Ouagadougou, Burkina Faso-implications for women's and children's health, Environ. Monit. Assess., Springer International Publishing,

186, 4479-4492, Available from: http://link.springer.com/10.1007/s10661-014-3712-y (accessed 9 February 2017).

Titcombe, M.E. and Simcik, M. (2011) Personal and indoor exposure to PM2.5 and polycyclic aromatic hydrocarbons in the southern highlands of Tanzania: A pilot-scale study, Environ. Monit. Assess., 180, 461-476.

Tumwesige, V., Fulford, D. and Davidson, G. (2014) Biogas appliances in Sub-Sahara Africa, Biomass and Bioenergy, 70, 40-50.

Tumwesige, V. 2017 Adaptation of small scale biogas digesters in sub-Sahara Africa, PhD thesis University of Aberdeen. 
586 World Health Organization. (2016) Ambient (outdoor) air quality and health, WHO, World $587 \quad$ Health Organization.

588 Zhou, Z., Dionisio, K.L., Arku, R.E., Quaye, A., Hughes, A.F., Vallarino, J., Spengler, J.D., 589 Hill, A., Agyei-Mensah, S. and Ezzati, M. (2011) Household and community povety, 590 biomass use, and air pollution in Accra, Ghana, Pnas, 108, 11028-11033. 
Page $\mathbf{3 1}$ of $\mathbf{3 1}$ 